\title{
Cortical laminar necrosis in dengue encephalitis—a case report
}

\author{
Ravindra Kumar Garg ${ }^{1 *}$, Imran Rizvi ${ }^{1}$, Rajan Ingole ${ }^{1}$, Amita Jain² ${ }^{2}$ Hardeep Singh Malhotra ${ }^{1}$, Neeraj Kumar ${ }^{1}$ \\ and Dhruv Batra'
}

\begin{abstract}
Background: Dengue encephalitis is a rare neurological manifestation of dengue fever. Its clinical presentation is similar to other viral encephalitides and encephalopathy. No single specific finding on magnetic resonance imaging of dengue encephalitis has yet been documented. They are highly variable and atypical.

Case presentation: A 15-year boy presented with fever, the headache and altered sensorium of 12-day duration. On neurological examination, his Glasgow Coma Scale score was 10 (E3M4V3). There was no focal neurological deficit. Laboratory evaluation revealed leukopenia and marked thrombocytopenia. Dengue virus IgM antibody was positive both in serum and cerebrospinal fluid. Magnetic resonance imaging of the brain revealed signal changes in bilateral parietooccipital and left frontal regions (left hemisphere more involved than the right hemisphere). There was gyriform enhancement bilateral parietooccipital regions consistent with cortical laminar necrosis. Bilaterally diffuse subcortical white matter was also involved and subtle T2 hyperintensity involving both basal ganglia was noted. Gradient echo sequence revealed presence of hemorrhage in the subcortical white matter. Patient was treated conservatively and received platelet transfusion. Patient became fully conscious after 7 days.
\end{abstract}

Conclusion: In a patient with highly suggestive dengue elephalitis, we describe an unusual magnetic resonance imaging finding. This report is possibly the first instance of cortical laminar necrosis in such a setting.

Keywords: Cortical laminar necrosis, Encephalitis, Encephalopathy, Magnetic resonance imaging, Dengue virus, Case report

\section{Background}

Currently, dengue infection is endemic in more than 100 countries. The incidence of dengue has increased dramatically in recent decades. World Health Organization, currently, estimates that 390 million dengue infections occur per year, of which 96 million manifest clinically; about $2.5 \%$ of those affected dies. Dengue virus is a single-stranded RNA virus belonging to the Flaviviridae family. There are four serotypes of dengue virus (DENV1 to DENV-4), of which serotypes DENV-2 and DENV-3 have been implicated most frequently in dengue fever. The involvement of the central nervous system has been described with all 3 classical types of dengue, dengue fever, dengue hemorrhagic fever, and dengue shock syndrome [1].

\footnotetext{
* Correspondence: garg50@yahoo.com

'Department of Neurology, King George's Medical University, UP, Lucknow 226003, India

Full list of author information is available at the end of the article
}

Encephalitis has been reported worldwide as a severe complication in patients infected by dengue virus. Dengue virus encephalitis often presents as acute encephalitis syndrome during dengue epidemics and can be seen in all 3 classical types of dengue. Indirect mechanisms such as impaired kidney and liver dysfunctions, hypoxicischemic insults, and other metabolic disorders can affect brain function and clinically present as encephalopathy. In addition to direct viral involvement of brain, there are several other pathologies like ischemic and hemorrhagic strokes, subdural hematoma, cerebral venous thrombosis, and acute disseminated encephalomyelitis that can affect the brain [2-6] (Table 1).

In most cases with dengue virus encephalitis, neuroimaging is normal [7]. Whenever, neuroimaging is abnormal, changes are usually non-specific in terms of etiology but may provide a hint towards the possible pathophysiological process. We report a case highly 
Table 1 Neuroimaging spectrum of dengue-associated encephalitis/encephalopathy

\begin{tabular}{|c|c|c|}
\hline Clinical syndrome & Neuroimaging features & Pathogenesis \\
\hline \multicolumn{3}{|l|}{ Diffuse brain involvement } \\
\hline Encephalopathy & Often normal & $\begin{array}{l}\text { Impaired liver and renal dysfunction } \\
\text { Ischemic-hypoxemic injury }\end{array}$ \\
\hline Acute encephalitis & $\begin{array}{l}\text { Usually normal; diffuse cortical and } \\
\text { periventricular, hyperintensities }\end{array}$ & Direct viral invasion of brain \\
\hline Acute hemorrhagic encephalitis & $\begin{array}{l}\text { GRE sequence shows areas of blooming } \\
\text { indicating hemorrhage }\end{array}$ & Direct viral invasion of brain \\
\hline $\begin{array}{l}\text { Acute disseminated } \\
\text { encephalomyelitis }\end{array}$ & Periventricular white matter lesions & Post-infectious demyelination \\
\hline \multicolumn{3}{|l|}{ Vascular complications } \\
\hline Cerebral venous thrombosis & Thrombosis of venous system of brain & Severe dehydration and hypotension \\
\hline Intracerebral hemorrhage & $\begin{array}{l}\text { Cerebral parenchymal, subdural or subarachnoidal } \\
\text { hematoma }\end{array}$ & $\begin{array}{l}\text { Thrombocytopenia, disseminated } \\
\text { intravascular coagulation and associated } \\
\text { coagulopathies }\end{array}$ \\
\hline Ischemic stroke & Multiple infarctions & Vasculitis, infective thromboembolism \\
\hline \multicolumn{3}{|l|}{ Focal encephalitis } \\
\hline Cerebellitis Rhombencephalitis & Hyperintensities in brainstem and cerebellum & Direct viral invasion \\
\hline
\end{tabular}

suggestive of dengue encephalitis with an unusual magnetic resonance imaging finding in brain.

\section{Case presentation}

A 15-year-old boy presented to our University Hospital, a tertiary care neurology facility, with fever, headache, and altered sensorium of 12-day duration. At admission, he was febrile $\left(101{ }^{\circ} \mathrm{F}\right)$, with a pulse rate of $110 / \mathrm{min}$ and a blood pressure recording of $114 / 74 \mathrm{mmHg}$; his Glasgow Coma Scale score was 10 (E3M4V3). There were no petechiae or signs of bleeding over the skin or any mucosal surface. There was no focal neurological deficit and neurological examination was normal, including (absence of) signs of meningeal irritation. Laboratory evaluation revealed the following estimations: hemoglobin of $11 \mathrm{~g} / \mathrm{dl}$, total leukocyte count of 3300 cells $/ \mathrm{mm}^{3}$, and platelet count of 22,000 cells $/ \mathrm{mm}^{3}$ which dropped to 8000 cells/ $\mathrm{mm}^{3}$ on next day. His aspartate aminotransferase level was $155 \mathrm{U} / \mathrm{L}$, alanine aminotransferase was $140 \mathrm{U} / \mathrm{L}$ and alkaline phosphatase was $56 \mathrm{U} / \mathrm{L}$. Additional biochemical parameters, renal function tests, blood sugar, electrolytes, and arterial blood gas analysis, were normal. Malarial parasite was not detected in the peripheral blood smear. The cerebrospinal fluid examination, cytological and biochemical, was normal. IgM antibody against dengue virus was positive both in serum and cerebrospinal fluid; meanwhile, dengue NS1 antigen was negative. Electroencephalography revealed generalized slowing. On magnetic resonance imaging of the brain, signal changes were seen in bilateral parietooccipital and left frontal region (left hemisphere was more involved than the right hemisphere). There were diffuse subcortical white matter changes along with suggestion of hemorrhage on gradient echo sequence. Subtle hyperintensity on T2 W images was also noted in bilateral basal ganglia. Gadoliniumcontrast study revealed a gyriform enhancement suggestive of cortical laminar necrosis (Fig. 1). He was managed conservatively and given platelet transfusion. The patient responded well to management and became fully conscious in 7 days.

\section{Discussion}

Cortical laminar necrosis is an imaging term classically used to describe high-intensity cortical lesions in a gyriform distribution on T1-weighted magnetic resonance imaging. Cortical laminar necrosis is, pathologically, characterized as necrosis of particular cortical laminae involving neurons, glial cells, and cerebral blood vessels. Cortical laminar necrosis is predominantly caused by hypoxia and metabolic disorders, like hypoglycemia, intoxication, hypoxic-ischemic encephalopathy, renal and hepatic dysfunction, but may also be seen in patients with encephalitis [8-10]. We describe the occurrence of cortical laminar necrosis in a setting highly suggestive of dengue infection, possibly the first instance, in a 15year-old boy.

Dengue virus was, at large, considered a nonneurotropic virus. With an increase in awareness and improvement in laboratory techniques, dengue virus or dengue viral components are being isolated from brain tissue or from cerebrospinal fluid specimens [11-13]. The mechanism of dengue virus invasion of the central nervous system, and its consequences, is not completely understood. It is supposed that the neurological complications of dengue virus are caused by many mechanisms, singularly or in a combination, like systemic metabolic 


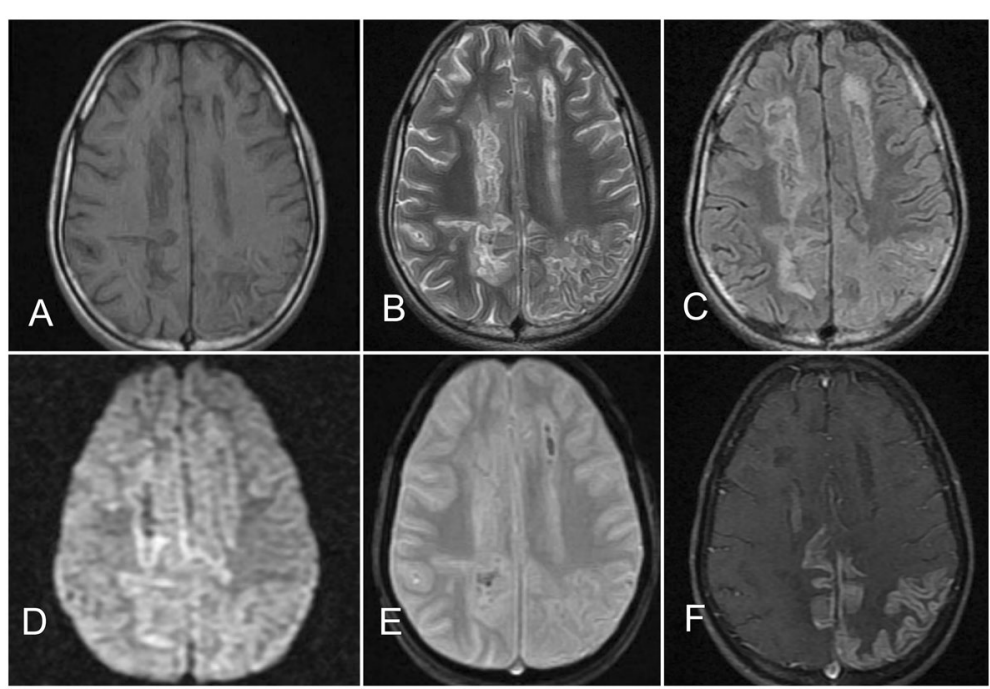

Fig. 1 Axial sections of MRI of the brain depict curvilinear hyperintense cortical lesions in bilateral parietal and occipital areas on T1 W (a), T2 W (b) and T2 fluid attenuated inversion recovery (c) sequences. Mild gyral diffusion restriction is noted on diffusion weighted sequence (d) while blooming is seen on gradient echo sequence $(\mathbf{e})$. Post-contrast T1 W sequence (f) depicts gyral enhancement

abnormalities, liver and kidney dysfunctions, direct infection, post-infectious immune disorders, abnormal vascular permeability and flow abnormalities, and coagulopathies. Possibly, the virus enters the central nervous system via infected macrophages. In an experimental study, Bordignon and co-workers noted that a mutant dengue virus-1 escaped immune defense mechanism of the body and caused a severe meningo-encephalitis in mice [14]. In another study that included 84 patients with fatal dengue meningoencephalitis, dengue virus serology in cerebrospinal fluid specimens was positive in $50 \%$ of the patients. These findings indicate that dengue virus has neurotropic properties and actively invades central nervous system [11]. Dengue virus-associated cerebrospinal fluid pleocytosis, cerebral parenchymal inflammatory cell infiltrates, and intrathecal synthesis of dengue-specific antibodies also indicate active viral invasion of brain [15].

A wide variety of neuroimaging changes have been described in dengue encephalitis. Not all patients have neuroimaging abnormalities. Bhoi and co-workers, in a series of 20 patients, noted neuroimaging abnormalities in $50 \%$ of patients with dengue virus infection [16]. Multifocal hyperintensities in bilateral periventricular zones, including basal ganglia, may be seen on T2 W and fluid attenuated inversion recovery sequences [3]. Brainstem, cerebellum, corpus callosum and thalamus may also be involved [17]. In many patients with acute hemorrhagic encephalitis, gradient echo sequences reveal patchy areas of blooming suggestive of hemorrhage [18]. In many patients with dengue infection, encephalopathy is being attributed to acute disseminated encephalomyelitis. In such cases, T2-weighted magnetic resonance imaging reveals signal abnormalities in the subcortical and periventricular white matter, with or without gray matter involvement. Dengue-associated acute disseminated encephalomyelitis, being an immune mediated disorder of the central nervous system, has been shown to respond well to intravenous methylprednisolone [2].

In our case, we kept the possibility of direct dengue virus infection as the foremost cause of cortical laminar necrosis. Metabolic abnormalities, as depicted by mildly deranged liver functions, was kept as the next possibility. As the patient was hemodynamically stable, hypoxicischemic insult seems unlikely and the spatial distribution of lesions did not favor the occurrence of posterior leukoencephalopathy. Although evidence of blooming is known in patients with encephalitis, thrombocytopenia in the present scenario might have had a contributory role in the characteristic radiological presentation.

Diagnosis of dengue encephalitis is often not difficult in the setting of a dengue epidemic and a patient presenting with febrile encephalopathy and demonstration of anti-dengue IgM antibodies or dengue genomic material in serum and/or cerebrospinal fluid could be diagnosed as dengue encephalitis [19]. However, in low incidence areas and non-endemic zones, a high index of suspicion should be kept and an effort should be made to rule out other causes of viral encephalitis prevalent in that area [20]. Dengue NS-1 antigen might not be demonstrable in all cases especially those who present after 1 week of onset of symptoms. A low platelet count and altered liver and renal function may help in making diagnosis of dengue encephalitis/encephalopathy. 


\section{Conclusion}

There is no characteristic neuroimaging finding in dengue encephalitis. Frequently, changes in white matter and deep gray matter have been described. We describe an unusual magnetic resonance imaging finding in a patient dengue encephalitis. Cortical laminar necrosis has never been described in dengue encephalitis.

\section{Abbreviations}

DENV: Dengue virus; RNA: Ribonucleic acid

\section{Acknowledgement}

None.

\section{Funding}

Not applicable.

\section{Availability of data and materials}

All the data supporting our findings is contained within the manuscript.

\section{Authors' contributions}

RKG: Case evaluation, contributing in work up of the patient and writing the manuscript. IR: Case evaluation, contributing in work up of the patient and writing the manuscript. Rl: Case evaluation, contributing in work up of the patient and writing the manuscript. AJ: Virological evaluation and manuscript review. HSM: Review of literature and writing the manuscript. NK: Review of literature and writing the manuscript. DB: Case evaluation, contributing in work up of the patient and writing the manuscript. All authors read and approved the final manuscript.

\section{Competing interest}

On behalf of all authors, the corresponding author states that there is no competing of interest.

\section{Consent for publication}

Written informed consent was obtained from the patient/legal guardian.

\section{Ethics approval and consent to participate}

Not applicable.

\section{Publisher's Note}

Springer Nature remains neutral with regard to jurisdictional claims in published maps and institutional affiliations.

\section{Author details}

'Department of Neurology, King George's Medical University, UP, Lucknow 226003, India. ²Department of Microbiology, King George's Medical University, UP, Lucknow 226003, India.

Received: 4 January 2017 Accepted: 1 April 2017

Published online: 20 April 2017

\section{References}

1. World Health Organization. Dengue and severe dengue: Fact sheet, Updated July 2016. http://www.who.int/mediacentre/factsheets/fs117/en/; Assessed 28 Dec 2016

2. Viswanathan S, Botross N, Rusli BN, Riad A. Acute disseminated encephalomyelitis complicating dengue infection with neuroimaging mimicking multiple sclerosis: a report of two cases. Mult Scler Relat Disord. 2016:10:112-5.

3. Porwal J, Chauhan A. Dengue encephalitis. J Assoc Physicians India. 2016;64: 99-100.

4. Vasanthi N, Vairamon PM, Gowtham T, Das AK. Unusual presentation of dengue fever-cerebral venous thrombosis. J Clin Diagn Res. 2015:9:OD09-10.

5. Sam JE, Gee TS, Nasser AW. Deadly intracranial bleed in patients with dengue fever: a series of nine patients and review of literature. J Neurosci Rural Pract. 2016;7:423-34.
6. Jayasinghe NS, Thalagala E, Wattegama M, Thirumavalavan K. Dengue fever with diffuse cerebral hemorrhages, subdural hematoma and cranial diabetes insipidus. BMC Res Notes. 2016;9:265.

7. Baldaçara L, Ferreira JR, Filho LC, Venturini RR, Coutinho OM, Camarço WC, Fernandes CC, Júnior EV. Behavior disorder after encephalitis caused by dengue. J Neuropsychiatry Clin Neurosci. 2013;25:E44.

8. Niwa T, Aida N, Shishikura A, Fujita K, Inoue T. Susceptibility-weighted imaging findings of cortical laminar necrosis in pediatric patients. AJNR Am Neuroradiol. 2008;29(9):1795-8.

9. Liu X, Zhao X, Yang J, Han X, Ruan X, Du Y. Cortical laminar necrosis following the rapid correction of drug-induced hyponatremia. Neurol Sci. 2015;36:1725-7.

10. Rajasekharan C, Jithesh B, Renjith SW. Cortical laminar necrosis due to hypoglycaemic encephalopathy:-images in medicine. BMJ Case Rep. 2013.

11. Araújo FM, Araújo MS, Nogueira RM, Brilhante RS, Oliveira DN, Rocha MF, Cordeiro RA, Araújo RM, Sidrim JJ. Central nervous system involvement in dengue: a study in fatal cases from a dengue endemic area. Neurology. 2012;78:736-42.

12. Araújo FM, Brilhante RS, Cavalcanti LP, Rocha MF, Cordeiro RA, Perdigão AC, Miralles IS, Araújo LC, Araújo RM, Lima EG, Sidrim JJ. Detection of the dengue non-structural 1 antigen in cerebral spinal fluid samples using a commercially available enzyme-linked immunosorbent assay. J Virol Methods. 2011;177:128-31.

13. Miagostovich MP, Ramos RG, Nicol AF, Nogueira RM, Cuzzi-Maya T, Oliveira AV, Marchevsky RS, Mesquita RP, Schatzmayr HG. Retrospective study on dengue fatal cases. Clin Neuropathol. 1997:16:204-8.

14. Bordignon J, Strottmann DM, Mosimann AL, Probst CM, Stella V, Noronha L, Zanata SM, Dos Santos CN. Dengue neurovirulence in mice: identification of molecular signatures in the E and NS3 helicase domains. J Med Virol. 2007; 79:1506-17.

15. Puccioni-Sohler M, Soares CN, Papaiz-Alvarenga R, Castro MJ, Faria LC, Peralta JM. Neurologic dengue manifestations associated with intrathecal specific immune response. Neurology. 2009;73:1413-7.

16. Bhoi SK, Naik S, Kumar S, Phadke RV, Kalita J, Misra UK. Cranial imaging findings in dengue virus infection. J Neurol Sci. 2014;342:36-41.

17. Verma R, Bharti K, Mehta M, Bansod A. Rhombencephalitis associated with dengue fever. J Clin Virol. 2016:78:99-101.

18. Nadarajah J, Madhusudhan KS, Yadav AK, Gupta AK, Vikram NK. Acute hemorrhagic encephalitis: an unusual presentation of dengue viral infection. Indian J Radiol Imaging. 2015;25:52-5

19. Soares CN, Faria LC, Peralta JM, de Freitas MR, Puccioni-Sohler M. Dengue infection: neurological manifestations and cerebrospinal fluid (CSF) analysis. J Neurol Sci. 2006;249:19-24.

20. Garg RK, Malhotra HS, Gupta A, Kumar N, Jain A. Concurrent dengue virus and Japanese encephalitis virus infection of the brain: is it co-infection or co-detection? Infection. 2012:40:589-93.
Submit your next manuscript to BioMed Central and we will help you at every step:

- We accept pre-submission inquiries

- Our selector tool helps you to find the most relevant journal

- We provide round the clock customer support

- Convenient online submission

- Thorough peer review

- Inclusion in PubMed and all major indexing services

- Maximum visibility for your research

Submit your manuscript at www.biomedcentral.com/submit
Biomed Central 